\title{
Caracterização fenotípica e molecular de isolados de Staphylococcus spp. obtidos de leite de ovelhas do Município de Chapecó-SC
}

\author{
Phenotypic and molecular characterization of isolates of \\ Staphylococcus spp. obtained from sheep milk Chapecó-SC
}

\author{
Alais Maria Dall Agnol ${ }^{1}$; Marielly Bastos Cavalcante ${ }^{2}$; Chirles Araújo de França ${ }^{3}$; \\ Carina da Costa Krewer"; Anderson Antônio de Queiros ${ }^{5}$; Mateus Matiuzzi da \\ Costa $^{6}$; José Francisco Manta Bragança ${ }^{7}$; Lilian Kolling Girardini ${ }^{7 *}$
}

\begin{abstract}
Resumo
O presente trabalho teve como objetivos determinar o perfil de sensibilidade aos antimicrobianos e avaliar a presença de mecanismos de resistência antimicrobiana em Staphylococcus spp. $(n=36)$ isolados de mastite em ovelhas do município de Chapecó-SC. O potencial para produção de biofilme foi determinado pelos testes fenotípicos de Agar Vermelho Congo, DAPI e Violeta de Genciana e por teste molecular pela técnica de PCR para a detecção do gene icaD. Para determinar o perfil de resistência aos antimicrobianos, foi realizado o teste de difusão em disco e detecção dos genes de resistência blaZ, mecA, erm (A, B e C) e msrA. O teste da bomba de efuxo foi realizado através do crescimento das culturas em Agar Muller Hinton contendo brometo de etídio. Os resultados mostraram que $1(2,78 \%), 36(100 \%)$ e $10(27,78 \%)$ isolados foram considerados produtores de biofilme pelos testes de Agar Vermelho Congo, DAPI e Violeta de Genciana, respectivamente, enquanto que o gene ica $\mathrm{D}$ foi observado em apenas $2(5,55 \%)$ isolados. O menor percentual de sensibilidade foi observado para ampicilina $(58,33 \%)$ e penicilina $(58,33 \%)$. Os isolados avaliados foram positivos para os genes de resistência blaZ $(58,33 \%)$ e $m s r A(11,11 \%)$. Nenhum isolado apresentou os genes de resistência erm (A, B, C) e apenas uma amostra foi positiva para o teste da bomba de efluxo.
\end{abstract}

Palavras-chave: Mastite, ovinos, genes de resistência, bomba de efluxo, biofilme, PCR

\begin{abstract}
This study aimed to determine the antimicrobial susceptibility profile and to assess the presence of mechanisms of antimicrobial resistance in Staphylococcus spp. $(n=36)$ isolated from mastitis in sheep's Chapecó-SC. The potential for biofilm production was determined by phenotypic tests of Congo Red Agar, DAPI and Gentian Violet and by PCR for the detection of $i c a \mathrm{D}$ gene. To evaluate the antimicrobial resistance testing was performed disk diffusion and detection of resistance genes blaZ, mecA, erm $\mathrm{A}$, erm $\mathrm{B}$ and erm $\mathrm{C}$ and $m s r \mathrm{~A}$ also performed by PCR. The pump test was conducted by efuxo crop growth Muller Hinton agar containing ethidium bromide. The results showed that $1(2,78 \%), 36(100 \%)$ and
\end{abstract}

1 Graduada em Medicina Veterinária pela Universidade do Oeste de Santa Catarina, UNOESC, Campus Xanxerê, Xanxerê, SC. E-mail: alaisagnol@hotmail.com

2 Mestre em Ciência Animal, Universidade Federal do Vale do São Francisco, UNIVASF, Campus Ciências Agrárias, Petrolina, PE. E-mail: mari.cavalcante@yahoo.com.br

3 Mestre em Ciência Animal, UNIVASF, Petrolina, PE. E-mail: chirleskb@yahoo.com.br

${ }^{4}$ Mestre em Biociência Animal, Universidade Federal Rural de Pernambuco, UFRPE, Recife, PE. E-mail: carikrewer@hotmail.com Discente em Medicina Veterinária pela UNOESC, Campus Xanxerê, Xanxerê, SC. E-mail: anderson_nt08@hotmail.com Prof. da UNIVASF, Campus Ciências Agrárias, Petrolina, PE. E-mail: mateus.costa@univasf.edu.br

Profs. da UNOESC Campus Xanxerê, Xanxerê, SC. E-mail: jose.braganca@unoesc.edu.br; lilian.kolling@unoesc.edu.br Autor para correspondência 
$10(27,78 \%)$ isolates were considered to produce a biofilm on Congo Red Agar test, Gentian Violet and DAPI, respectively, while the gene icaD was observed in only $2(5.55 \%)$ isolates. The lowest percentage of sensitivity was observed for ampicillin $(58.33 \%)$ and penicillin $(58.33 \%)$. All strains tested were negative for the mec $\mathrm{A}$, erm $\mathrm{A}, \operatorname{erm} \mathrm{B}$ and $\operatorname{erm} \mathrm{C}$ genes. However, the isolates were positive for other resistance genes, being the blaZ and the $m s r \mathrm{~A}$, with percentages of positivity of $58.33 \%$ and $11.11 \%$ respectively. Only one sample was positive for efflux pump test.

Key words: Mastitis, sheep, resistance genes, efflux pump, biofilm, PCR

\section{Introdução}

A ovinocultura brasileira é tradicionalmente voltada para a produção de lã e carne. $O$ rebanho nacional em 2010 era de aproximadamente 15,3 milhões de animais (IBGE, 2012), já em Santa Catarina o rebanho é de 253.350 mil ovinos (IBGE, 2012), tendo como característica a produção em pequenas propriedades. No entanto, a produção de leite ovino vem apresentando crescimento na última década. Atualmente Santa Catarina é o maior produtor de leite ovino do país, com um rebanho de aproximadamente quatro mil ovelhas leiteiras (EPAGRI, 2012).

A mastite é uma importante doença de ovelhas, que provoca graves perdas econômicas, mesmo nos rebanhos com vocação para produção de carne (MORONI et al., 2007). Embora a mastite clínica seja responsável por perdas expressivas, a mastite subclínica assume elevada relevância econômica em virtude dos prejuízos na produção e da maior ocorrência, comparativamente às formas clínicas da infecção (FONSECA; SANTOS, 2000).

Os estafilococos são considerados os mais importantes agentes causadores da mastite (AIRESDE-SOUZA et al., 2007; TAPONEN; PYORALA, 2009) sendo que o grupo dos Staphylococcus coagulase negativa são a principal causa de mastite em pequenos ruminantes (BERGONIER et al., 2003).

O tratamento antimicrobiano é comumente necessário nos casos de mastite (CONTRERAS et al, 2007; PYÖRÄLÄ; TAPONEN, 2009) e diferentes antimicrobianos têm sido recomendados na terapia intramamária em ovinos (NACCARI et al., 2003). No entanto, há evidências de que a resistência aos antimicrobianos vem aumentando em estafilococos isolados dos animais destinados à alimentação humana (PHILLIPS et al., 2004). O surgimento de resistência a múltiplas drogas em Staphylococcus spp. é responsável por prejuízos à ovinocultura, muitas vezes devido ao insucesso nos tratamentos. Além disso, o risco de veiculação de bactérias resistentes a diferentes antimicrobianos, através de produtos lácteos, torna-se risco à saúde pública (KUMAR; YADAV; SINGH, 2009; SAWANT; GILLESPIE; OLIVER, 2009).

Importantes mecanismos conferem resistência aos beta-lactâmicos em estafilococos (OLSEN; CHRISTENSEN; AARESTRUP, 2006). O mais importante é a produção de beta-lactamase, mediada pelo gene blaZ, que inativa a penicilina por hidrólise do anel beta-lactâmico (OLSEN; CHRISTENSEN; AARESTRUP, 2006; TAPONEN; PYORALA, 2009). Outro mecanismo envolve a produção de uma transpeptidase (proteína de ligação à penicilina) modificada, a PBP2a, codificada pelo gene mecA que confere resistência à meticilina (LOWY, 2003; KATAYAMA et al., 2005). Há também as bombas de efluxo, que são proteínas transportadoras envolvidas na extrusão de substâncias tóxicas do interior da célula para o meio externo e que estão associadas à resistência contra diversas drogas, como macrolídeos e lincosamidas (BJORLAND et al., 2005; HASSAN; SKURRAY; BROWN, 2007).

No Brasil, são poucas as informações referentes à mastite em ovelhas, bem como sobre os mecanismos de resistência aos antimicrobianos em Staphylococcus spp. isolados de casos de mastite. Dessa forma, o presente trabalho objetivou determinar o perfil de sensibilidade aos 
antimicrobianos e avaliar a presença de mecanismos de resistência antimicrobiana em Staphylococcus spp. isolados de mastite em ovelhas do município de Chapecó-SC.

\section{Material e Métodos}

\section{Local de execução e coleta de material}

As amostras são provenientes de um rebanho ovino com aptidão leiteira, composto por animais da raça Lacaune e mestiças (Lacaune x Ile de France e Lacaune x Texel) do município de Chapecó-SC. Para a coleta de leite os tetos foram previamente higienizados. Descartaram-se os primeiros jatos e, em seguida, foi realizada a antissepsia com álcool $70 \%$ para posterior coleta do leite. Cada amostra era composta por leite de ambos os tetos e, para o transporte, foram acondicionadas em caixas isotérmicas com gelo.

\section{Isolamento e identificação das amostras bacterianas}

Para o isolamento bacteriano, as amostras foram cultivadas em Agar sangue a 5\% e incubadas em estufa a $37^{\circ} \mathrm{C}$. A leitura das placas foi realizada após 24 e $48 \mathrm{~h}$, e os agentes bacterianos foram identificados por meio de características morfológicas, bioquímicas e tintoriais (QUINN et al., 1994). Para identificação bioquímica, foram utilizados os testes de glicose semi-sólida (GSS), manitol semi-sólido (MSS), Agar base púrpura (PAB), esculina, urease e DNAse.

\section{Teste de susceptibilidade aos antimicrobianos}

O perfil de sensibilidade dos micro-organismos foi determinado pelo método de difusão em disco Kirby-Bauer modificado (BAUER et al., 1966). Os isolados foram inoculados em caldo Müller Hinton até a obtenção de turvação conforme a escala 0,5 de Mac Farland. Com auxílio de um suabe, os isolados foram inoculados em placas de Petri contendo Agar
Müller Hinton. Em seguida, foram aplicados os discos impregnados com as drogas antimicrobianas: amoxicilina + ácido clavulânico $(10 \mu \mathrm{g})$, cefalexina $(30 \mu \mathrm{g})$, gentamicina $(10 \mu \mathrm{g})$, ampicilina $(10 \mu \mathrm{g})$, oxacilina $(1 \mu \mathrm{g})$, cefalotina $(30 \mu \mathrm{g})$, neomicina (30 $\mu \mathrm{g})$, penicilina $\mathrm{G}$ (10UI), eritromicina (15 $\mu \mathrm{g})$, enrofloxacina $(5 \mu \mathrm{g})$, tetraciclina $(30 \mu \mathrm{g})$, novobiocina $(30 \mu \mathrm{g})$ e ceftiofur $(30 \mu \mathrm{g})$. As placas foram incubadas em estufa durante $18-24 \mathrm{~h}$ a $37^{\circ} \mathrm{C}$. Após a leitura dos halos determinou-se o perfil de sensibilidade dos isolados.

\section{Produção de biofilme}

A produção de biofilme foi avaliada, fenotipicamente, por meio de três testes: Agar Vermelho Congo, aderência em microplacas e microscopia de fluorescência. As amostras foram cultivadas em Agar Vermelho Congo conforme descrições de Greco et al. (2008). Após a incubação, os isolados que demonstraram colônias pretas foram considerados produtores de biofilme.

O método de aderência em microplacas foi realizado segundo Merino et al. (2009). A absorbância foi determinada em $620 \mathrm{~nm}$ (Leitor de Elisa, modelo Expert PLUS). Os isolados foram testados em triplicata, sendo utilizadas cepas controle positivo e negativo. Poços não inoculados contendo TSB (Tryptone Soya Broth) e glicose serviram como teste em branco.

Para verificação da produção de biofilme pela microscopia de fluorescência, utilizouse metodologia citada por Feazel et al. (2009) com algumas modificações. Os isolados foram inoculados em TSB e incubados a $37^{\circ} \mathrm{C}$ por $24 \mathrm{~h}$. Posteriormente, foram transferidos $200 \mu \mathrm{L}$ do inóculo para placas de Petri contendo TSB. Em seguida, adicionaram-se lamínulas que, após $24 \mathrm{~h}$ de incubação a $37^{\circ} \mathrm{C}$, foram retiradas, coradas com $100 \mu \mathrm{L}$ de DAPI (4,6-diamino-2-fenilindol, Sigma $^{\circledR}$ ) a $2 \mu \mathrm{g} / \mathrm{mL}$ e imediatamente observadas em microscópio de fluorescência. 
Caracterização molecular dos isolados de (resistência a meticilina), blaZ (resistência aos Staphylococcus spp.

$\beta$-lactâmicos), erm $\mathrm{A}$, erm $\mathrm{B}$ e erm $\mathrm{C}$ (resistência a

A caracterização molecular dos isolados de Staphylococcus spp. foi realizada pela amplificação dos genes ica $\mathrm{D}$ (produção de biofilme), mecA eritromicina) e msrA (bomba de efluxo), por meio dos oligonucleotídeos iniciadores descritos na tabela 1 .

Tabela 1. Iniciadores utilizados para caracterização molecular dos isolados de Staphylococcus spp.

\begin{tabular}{|c|c|c|c|}
\hline Iniciador & Sequência $\left(5^{\prime}-3^{\prime}\right)$ & Fragmento & Referência \\
\hline$i c a \mathrm{DF}$ & AAGCCCAGACAGAGGCAATATCCA & 230 & Greco et al. (2008) \\
\hline$i c a \mathrm{DR}$ & AGTACAAACAAACTCATCCATCCGA & & \\
\hline$m e c \mathrm{AF}$ & CGGTAACATTGATCGCAACGTTCA & 214 & Murakami et al. (1991) \\
\hline mecAR & CTTTGGAACGATGCCTAATCTCAT & & \\
\hline blaZF & AAGAGATTTGCCTATGCTTC & 517 & Sawant, Gillespie e Oliver (2009) \\
\hline blaZR & GCTTGACCACTTTTATCAGC & & \\
\hline ermAF & ATCGGATCAGGAAAAGGACA & 486 & Sawant, Gillespie e Oliver (2009) \\
\hline ermAR & CACGATATTCACGGTTTACCC & & \\
\hline ermBF & AAGGGCATTTAACGACGAAA & 423 & Sawant, Gillespie e Oliver (2009) \\
\hline ermBR & CTGTGGTATGGCGGGTAAGT & & \\
\hline erm CF & TGAAATCGGCTC AGGAAAAG & 272 & Sawant, Gillespie e Oliver (2009) \\
\hline erm $\mathrm{CR}$ & CAAACCCGTATTCCACGATT & & \\
\hline$m s r \mathrm{AF}$ & TGGTACTGGCAAAACCACAT & 1000 & Sawant, Gillespie e Oliver (2009) \\
\hline msrAR & AAACGTCACGCATGTCTTCA & & \\
\hline
\end{tabular}

Fonte: Elaboração dos autores.

Como template foi utilizado o DNA termoextraído, sendo que $4 \mu \mathrm{L}$ desta suspensão foram aplicados em $21 \mu \mathrm{L}$ do mix contendo 15 pmol dos iniciadores, $200 \mathrm{mM}$ dos desoxirribonucleotídeos, tampão Taq 1x e 5 U de Taq (CENBIOT, UFRGS). Esta mistura foi levada ao termociclador e submetida a 35 ciclos constituídos de $30 \mathrm{~s}$ a $94^{\circ} \mathrm{C}, 30 \mathrm{~s}$ na temperatura ideal de anelamento de cada iniciador e 3 min a $72^{\circ} \mathrm{C}$. O resultado da PCR foi verificado em gel de agarose a $1,5 \%$, corado com brometo de etídio e documentado em sistema de captura de imagem com câmera digital.

\section{Resultados}

A partir da análise microbiológica do leite foram obtidos 36 isolados bacterianos, todos classificados como pertencentes ao gênero Staphylococcus, sendo $6(16,66 \%)$ identificados como Staphylococcus epidermidis, $4(11,11 \%)$ como S. simulans, 1 $(2,77 \%)$ como S. lentus, $3(8,33 \%)$ como $S$. aureus e $2(5,55 \%)$ como $S$. intermedius. Vinte $(55,55 \%)$ isolados foram identificados somente como Staphylococcus spp.

Em relação ao perfil de sensibilidade aos antimicrobianos, observa-se que as drogas que apresentaram menor percentual de sensibilidade foram a ampicilina e a penicilina (Tabela 2). Nove $(25 \%)$ isolados foram resistentes a dois ou mais antimicrobianos simultaneamente. 
Tabela 2. Percentual de sensibilidade aos antimicrobianos de acordo com cada espécie de Staphylococcus isolada de leite de ovelhas com mastite.

\begin{tabular}{cccccccccccccc}
\hline Espécies de & \multicolumn{11}{c}{ \% DE SENSIBILIDADE AOS ANTIMICROBIANOS } \\
\hline Staphylococcus (S.) & GEN & NEO & CFE & CFL & CTF & ENO & AMC & ERI & NOV & OXA & TET & AMP & PEN \\
S. epidermidis & 100 & 100 & 100 & 100 & 100 & 100 & 100 & 83,33 & 83,33 & 100 & 66,67 & 100 & 66,67 \\
S. simulans & 100 & 100 & 100 & 100 & 100 & 100 & 100 & 100 & 50 & 100 & 75 & 75 & 100 \\
S. lentus & 100 & 100 & 100 & 100 & 100 & 100 & 100 & 0 & 0 & 0 & 100 & 0 & 0 \\
Staphylococcus aureus & 100 & 100 & 100 & 100 & 100 & 100 & 66,67 & 100 & 100 & 100 & 33,33 & 66,67 & 66,67 \\
S. intermedius & 100 & 100 & 100 & 100 & 100 & 100 & 50 & 100 & 100 & 100 & 0 & 0 & 0 \\
Staphylococcus spp & 100 & 100 & 100 & 100 & 100 & 100 & 95 & 90 & 100 & 90 & 80 & 85 & 90 \\
\hline
\end{tabular}

Fonte: Elaboração dos autores.

O gene blaZ foi observado em 58,33\% dos isolados. Todos os isolados avaliados foram negativos para os genes mec $\mathrm{A}$, erm $\mathrm{A}$, erm $\mathrm{B}$ e erm $\mathrm{C}$. Dezesseis isolados foram negativos para todos os genes de resistência avaliados.

Em relação ao teste fenotípico para detecção de mecanismo de efluxo, apenas um isolado foi considerado positivo. O gene msrA, por sua vez, foi observado em $4(11,11 \%)$ isolados. O gene icaD foi observado em apenas $2(5,55 \%)$ isolados, enquanto que $1(2,77 \%), 36(100 \%)$ e $10(27,77 \%)$ isolados foram considerados, fenotipicamente, produtores de biofilme pelos testes de Agar Vermelho Congo, DAPI e Violeta de Genciana, respectivamente.

\section{Discussão}

No Brasil, a mastite ocasionada principalmente por bactérias do gênero Staphylococcus vem causando grandes prejuízos (SANTOS et al., 2007) e sua ocorrência é relatada em muitos estados do país, tais como Pernambuco (OLIVEIRA et al., 2007), Sergipe (MELO et al., 2008), Bahia (COUTINHO et al., 2006), São Paulo (NUNES et al., 2008; HERNANDES; LUCHEIS, 2006), Rio Grande do Sul (VAZ, 1996; FERNANDES; CARDOSO, 1985) e Santa Catarina (DRESCHER et al., 2010).

A maioria (80\%) dos isolados foi classificada no grupo Staphylococcus coagulase negativo (SCN). Estes resultados são semelhantes aos encontrados por Batavani et al. (2003), que ao avaliar 209 amostras de leite de ovelhas com mastite subclínica relataram o SCN como o agente mais prevalente. Da mesma forma, Coutinho et al. (2006) ao obter 33 isolados bacterianos a partir de leite de ovelhas, identificaram $57,6 \%$ dos isolados como $\mathrm{SCN}$. Contudo, nosso resultado indicou prevalência menor quando comparada à descrita por Della Libera et al. (2010) que, ao isolarem 130 bactérias provenientes de leite mastítico de ovelhas Santa Inês, encontraram 93,1\% de SCN. Estes resultados demonstram a importância deste agente como causador de mastites clínicas e subclínicas de difícil tratamento em ovinos (FTHENAKIS, 1994; STEFANAKIS et al., 1995; BURRIEL, 1997).

Em relação ao teste de suscetibilidade aos antimicrobianos, observou-se que as drogas menos eficientes pertencem ao grupo dos beta-lactâmicos (penicilina e ampicilina). Muitos mecanismos podem estar envolvidos com a resistência antimicrobiana, sendo que nos Staphylococcus spp., a perda da sensibilidade aos beta-lactâmicos está associada à presença do gene blaZ e mecA. Nos isolados do presente estudo, o gene blaZ pode ser associado à resistência nos testes fenotípicos, uma vez que este gene foi detectado em mais da metade dos isolados avaliados. O gene blaZ codifica uma beta-lactamase e é parte de um elemento genético móvel ou plasmídio, o qual frequentemente contém genes de resistência a outros antimicrobianos, como gentamicina e eritromicina (LOWY, 2003). Além 
disso, a transferência deste gene entre as espécies de Staphylococcus spp. tem contribuído para o aumento da resistência dessas bactérias aos beta-lactâmicos. A transferência de genes tem sido mencionada por Udo, Jacob e Mokadas (1997) e Jaffe et al. (1980), indicando que SCN, por exemplo, podem agir como reservatório de genes de resistência para $S$. aureus. Assim, é possível que as diferentes espécies de estafilococos que estão presentes na pele dos animais possam carrear e transferir o gene blaZ, disseminando a resistência aos beta-lactâmicos.

Nesse estudo, nota-se também que nove isolados apresentaram resistência múltipla a dois ou mais antimicrobianos avaliados. Segundo Freitas et al. (2005), os Staphylococcus spp. destacam-se pela capacidade de ser ou de tornarem-se resistentes a um grande número de antibióticos. Ferreira et al. (2006) associaram o agravamento da resistência bacteriana ao uso frequente e indiscriminado de antimicrobianos e aos mecanismos de transferência de resistência entre os micro-organismos. Este fato é comumente observado no campo em surtos de mastite (BRITO et al., 2001).

Dos 36 isolados, nenhum deles apresentou os genes erm (A, B e C), embora quatro deles se mostrem resistentes à eritromicina. A diferença de resistência fenotípica e genotípica à eritromicina pode ser explicada por algum outro mecanismo de resistência a macrolídeos ainda não estudado que pode ser usual em isolados de SCN (FIEBELKORN et al., 2003). A ocorrência de outros mecanismos de resistência para eritromicina são relacionadas com variações quanto à localização geográfica e uso terapêutico destes fármacos (GATERMANN; KOSCHINSKI; FRIEDRICH, 2007; PITKÄLÄ et al., 2004).

Observou-se que apenas quatro isolados apresentaram o gene msrA. Sawant, Gillespie e Oliver (2009), ao trabalharem com isolados de $S$. epidermidis de novilhas e vacas leiteiras, indicaram alta frequência do gene $m s r A$. Este gene é de fundamental importância, pois está relacionado com o mecanismo de bomba de efluxo, que favorece a resistência aos macrolídeos e tetraciclina. Todavia, outros mecanismos, como enzimas de modificação e proteção ribossômica, também podem contribuir para o aumento da resistência que os microorganismos apresentam a alguns antimicrobianos (GATERMANN; KOSCHINSKI; FRIEDRICH, 2007; HASSAN; SKURRAY; BROWN, 2007). Neste estudo, apenas um isolado foi produtor de bomba de efluxo, porém, quatro foram considerados positivos para o gene $m s r A$. Este fato sugere a possibilidade de que algumas condições ambientais ou a presença de genes acessórios podem influenciar o comportamento fenotípico na placa onde foi realizado o teste de bomba, gerando colônias que não expressam o gene msrA e, consequentemente, sendo consideradas fenotipicamente negativas para essa característica.

Foram observadas diferenças entre os resultados dos três testes fenotípicos relacionados à produção de biofilme, além de não haver isolados positivos, simultaneamente, para esses testes. No teste com o Agar Vermelho Congo, apenas 2,77\% dos isolados foram considerados positivos, resultado inferior ao encontrado por Freeman, Falkiner e Keane (1989), que detectaram a produção de biofilme em $77,78 \%$ dos isolados de SCN estudados. Ciftci et al. (2009), ao estudarem a produção de biofilme em Staphylococcus aureus de mastite bovina, encontraram $37,2 \%$ de isolados positivos para o teste do Agar Vermelho Congo, enquanto que para a PCR foi observado que $25,42 \%$ dos $S$. aureus possuíam os genes icaA e icaD.

Freeman, Falkiner e Keane (1989), propuseram o Agar Vermelho Congo como método alternativo para detectar a produção de biofilme. No entanto, esse teste se mostrou uma ferramenta pouco sensível para indicar a presença do biofilme nos isolados do presente estudo. Ciftci et al. (2009), afirmam que o Agar Vermelho Congo, apesar de ser um teste facilmente realizado em laboratório, ainda se constitui em um método pobre para a determinação da capacidade de produção de biofilme por isolados 
clínicos em um diagnóstico laboratorial. Mathur et al. (2006), avaliando a produção de biofilme por Staphylococcus spp., encontraram apenas 1,97\% de isolados positivos para o Agar Vermelho Congo, não recomendando o método para a detecção de formação de biofilme por isolados Staphylococcus spp.

A análise da produção de biofilme pela aderência em microplacas demonstrou que $27,77 \%$ das cepas aderiram à microplaca e foram consideradas produtoras de biofilmes. Esse resultado é inferior aos obtidos por Vasuvedan et al. (2003) que, ao estudar cepas de Staphylococcus aureus provenientes de mastite bovina encontraram $68,57 \%$ de cepas produtoras de biofilmes pela mesma técnica As diferenças encontradas para a produção fenotípica de biofilme podem ser explicadas devido às possíveis falhas na produção in vitro dessa estrutura em superfícies inertes, já que estas são altamente sensíveis às condições de crescimento (CRAMTON et al., 1999). Stepanovic et al. (2000) afirmam que o teste de aderência em placas é um dos métodos usados com maior frequência para quantificar a formação dos biofilmes produzidos pelos Staphylococcus spp., além de ser utilizado como um indicador de patogenicidade dos micro-organismos.

Quanto à avaliação da produção de biofilme por fluorescência, o teste com uso do DAPI apresentou resultado positivo para todos os isolados. Leroy et al. (2007), avaliaram a produção de biofilme pela bactéria marinha Pseudoalteromonas spp., em microplacas utilizando o corante DAPI para quantificar as bactérias em cada cavidade da placa e concluíram que, para uma primeira triagem, esse teste foi considerado apropriado. Já Feazel et al. (2009), utilizaram o DAPI para analisar a presença de biofilmes formados por micro-organismos que se encontram no interior de chuveiros residenciais. Os autores observaram que todas as amostras examinadas por microscopia mostraram evidências claras da morfologia do biofilme. Vale ressaltar que o uso do DAPI para análise de biofilme ainda é uma técnica pouco estudada, sendo necessários mais estudos para definir a especificidade da técnica.

No presente estudo, não foi observada relação entre os testes fenotípicos e o teste molecular (PCR para o gene icaD), resultado semelhante aos encontrados por Vasuvedan et al. (2003) e Arciola, Baldassarri e Montanaro (2001). Apesar de somente dois isolados apresentarem resultado positivo para o gene ica pela PCR, Arciola et al. (2002) afirmam que técnicas moleculares para identificação dos genes ica, que codificam a síntese do biofilme, representam uma ferramenta muito importante para a identificação precisa de cepas virulentas formadoras dessa estrutura. Com relação, especificamente, à concordância do teste de aderência em placas com o teste molecular, Bernadi (2005) encontrou 100\% dos isolados de SCN produtores de biofilme quanto à aderência em placas e 77\% também possuíam o gene icaA e icaD. Vasuvedan et al. (2003) encontraram $68,57 \%$ dos isolados produtores de biofilmes pela aderência em placas, no entanto no estudo genotípico, $100 \%$ dos isolados possuíam os genes ica $\mathrm{A}$ e ica $\mathrm{D}$, mostrando que o teste de aderência não apresentou boa concordância com o teste genotípico. Em nosso estudo a positividade para estes dois testes foi baixa.

A ocorrência de isolados produtores de biofilme é um achado preocupante, pois algumas evidências sugerem que determinadas espécies de Staphylococcus spp., que apresentam gene para a produção de biofilme, possuem capacidade de iniciar (BASELGA et al., 1993) e causar infecções intramamárias persistentes, além desta estrutura elevar a resistência à antibioticoterapia (CUCARELLA et al., 2004).

\section{Conclusões}

A maioria dos Staphylococcus spp. identificados nesse estudo foram classificados como pertencente ao grupo SCN. Em geral, os isolados foram menos sensíveis à ampicilina, penicilina e à enrofloxacina. Entre os genes de resistência, o blaZ foi encontrado nos isolados. Não há relação entre os testes 
fenotípicos e a técnica molecular para detecção da produção de biofilme. Apenas uma amostra foi positiva para o teste de bomba de efluxo. A identificação de tais características é fundamental, pois permite conhecer os principais mecanismos de patogenicidade destes micro-organismos, auxiliando na adoção de medidas adequadas para tratamento e controle da mastite nos ovinos.

\section{Agradecimentos}

Ao Conselho Nacional de Desenvolvimento Científico e Tecnológico - CNPq pela bolsa fornecida e à Fundação de Amparo à Ciência e Tecnologia do Estado de Pernambuco - FACEPE, pelo apoio financeiro (projetos do programa PPP/ FACEPE).

\section{Referências}

AIRES-DE-SOUSA, M.; PARENTE, C. E. S. R.; VIEIRA-DA-MOTA, O.; BONNA, I. C. F;, SILVA, D. A. LENCATRE, H. Characterization of Staphylococcus aureus isolates from buffalo, bovine, ovine and caprine milk samples collected in Rio de Janeiro, Brazil. Applied and Environmental Microbiology, Washington, v. 73, n. 12, p. 3845-3849, 2007.

ARCIOLA, C. R.; BALDASSARRI, L.; MONTANARO, L. Presence of $i c a \mathrm{D}$ genes and slime production in a collection of Staphylococcal strains from catheterassociated infections. Journal of Clinical Microbiology, Washington, v. 39, n. 6, p. 2151-2156, 2001.

ARCIOLA, C. R.; CAMPOCCIA, D.; GAMBERINI, S.; CERNELLATI, M.; DONATI, E.; MONTANARO, L. Detection of slime production by means of an optimized Congo red agar plate based on a colorimetric scale in Staphylococcus epidermidis clinical isolates genotyped for ica locus. Biomaterials, Amsterdam, v. 23, n. 21, p. 4233-4239, 2002.

BASELGA, R.; ALBIZU, I.; DE LA CRUZ, M.; DEL CACHO, E.; BARBERAN, M.; AMORENA, B. Phase variation of slime production in Staphylococcus aureus: implications in colonization and virulence. Infection and Immunity, Washington, v. 61, n. 11, p. 4857-4862, 1993.

BATAVANI, R. A.; MORTAZ, E.; FALAHIAN, K.; DAWOODI, M. A. Study on frequency, etiology and some enzymatic activities of subclinical ovine mastitis in Urmia, Iran. Small Ruminant Research, Amsterdam, v. 50, n. 1, p. 45-50, 2003.

BAUER, A. W.; KIRBY, W. M. M.; SHERRIS, J. C.; TURCK, M. Antibiotic susceptibility testing by a standardized single disk method. American Journal of Clinical Pathology, Chicago, v. 45, n. 4, p. 493-496, 1966.

BERGONIER, D.; CREMOUX, R.; RUPP, R.; LAGRIFFOUL, G.; BERTHELOT, X. Mastitis in small dairy ruminants. Veterinary Research, Paris, v. 34, n. 5, p. 689-716, 2003.

BERNADI, A. C. A. Estudo de amostras de Staphylococcus coagulase-negativa quanto à formação de biofilme. 2005. Tese (Doutorado) - Faculdade de Ciências Farmacêuticas. Universidade Estadual Paulista, Araraquara.

BJORLAND, J.; STEINUM, T.; KVITLE, B.; WAAGE, S.; SUNDE, M.; HEIR, E. Widespread distribution of disinfectant resistance genes among staphylococci of bovine and caprine origin in Norway. Journal of Clinical Microbiology, Washington, v. 43, n. 9, p. 4363-4368, 2005.

BRITO, M. A. V. P.; BRITO, J. R. F.; SILVA, M. A. S.; CARMO, R. A. Concentração mínima inibitória de dez antimicrobianos para amostras de Staphylococcus aureus isoladas de infecção intramamária bovina. Arquivo Brasileiro de Medicina Veterinária e Zootecnia, Belo Horizonte, v. 53, n. 5, p. 531-537, 2001.

BURRIEL, A. R. Dynamics of intramammary infection in sheep caused by coagulase negative Staphylococci and its influence on udder tissue and milk composition. Veterinary Record, London, v. 140, n. 16, p. 419-423, 1997.

CIFTCI, A.; FINDIK, A.; ONUK E, E.; SAVASAN, S. Detection of methicillin resistance and slime factor production of Staphylococcus aureus in bovine mastitis. Brazilian Journal of Microbiology, São Paulo, v. 40, n. 2, p. 254-261, 2009.

CONTRERAS, A.; SIERRA, D.; SÁNCHEZ, A.; CORRALES, J. C.; MARCO, J. C.; PAAPE, M. J.; GONZALO C. Mastitis in small ruminants. Small Ruminant Research, Amsterdam, v. 68, n. 1-2, p. 145153, 2007.

COUTINHO, D. A.; COSTA, J. N.; RIBEIRO, M. G.; TORRES, J. A. Etiologia e sensibilidade antimicrobiana in vitro de bactérias isoladas de ovelhas da raça Santa Inês com mastite subclínica. Revista Brasileira de Saúde e Produção Animal, Salvador, v. 7, n. 2, p. 139-151, 2006. 
CRAMTON, S. E.; GERKE, C.; SCHNELL, N .F.; NICHOLS, W. W.; GOTZ, F. The intercellular adhesion (ica) locus is present in Staphylococcus aureus and is required for biofilm formation. Infection and Immunity, Washington, v. 67, n. 10, p. 5427-5433, 1999.

CUCARELLA, C.; TORMA, M. A.; U'BEDA, C.; TROTONDA, M. P.; MONZO'N, M.; PERIS, C.; AMORENA, B.; LASA, I.; PENADE'S, J. R. Role of biofilm-associated protein Bap in the pathogenesis of bovine Staphylococcus aureus. Infection and Immunity, Washington, v. 72, n. 4, p. 2177-2185, 2004.

DELLA LIBERA, A. M. M. P.; BLAGITZ, M. G.; SOUZA, F. N.; BATISTA, C. F.; AZEDO, M. R.; BENITES, N. R.; MELVILLE, P. A.; GOMES, V. Antimicrobial susceptibility of coagulase-negative staphylococci isolated from meat-producing ewes with mastitis. Arquivo Brasileiro de Medicina Veterinária e Zootecnia, Belo Horizonte, v. 62, n. 6, p. 1499-1502, 2010.

DRESCHER, G.; MATTIELlO S. P.; PEIXOTO, R. M.; DE VARGAS, A. C.; MACIEL, M. N.; COSTA, M. M. Caracterização bioquímica e perfil de sensibilidade aos antimicrobianos de agentes bacterianos isolados de mastite subclínica ovina na Região Oeste de Santa Catarina. Ciência Animal Brasileira, Goiânia, v. 11, n. 1, p. 188-193, 2010.

EPAGRI. Ovinos de leite. 2012. Disponível em: $<$ http://www.epagri.sc.gov.br/index.php?option=com content\&view $=$ article $\& i d=3506:$ ovinos $-d e-$ leite $\&$ catid $=34$ :noticias-epagri\&Itemid $=51>. \quad$ Acesso em: 06 set. 2012.

FEAZEL, L. M.; BAUMGARTNER, L. K.; PETERSON, K. L.; FRANK, D. N.; HARRIS, J. K.; PACE, N. R. Oppotunistic pathogens enriched in showerhead biofilms. Microbiology, Washington, v. 106, n. 38, p. 16393-16399, 2009.

FERNANDES, J. C. T.; CARDOSO, M. R. I. Mamite ovina causada por Staphylococcus aureus. Primeira observação no Brasil. Arquivos da Faculdade de Veterinária, UFRGS, v. 13, n. 1, p. 71-74, 1985.

FERREIRA, L. M.; NADER FILHO, A.; OLIVEIRA, E. de; ZAFALON, L. F.; SOUZA, V. de. Variabilidade fenotípica e genotípica de estirpes de Staphylococcus aureus isoladas de caso de mastite subclínica bovina. Ciência Rural, Santa Maria, v. 36, n. 4, p. 1228-1234, 2006.

FIEBELKORN, K. R.; CRAWFORD, S. A.; MCELMEEL, M. L.; JORGENSEN, J. H. Practical disk diffusion method for detection of inducible clindamycin resistance in Staphylococcus aureus and coagulasenegative staphylococci. Journal of Clinical Microbiology, Washington, v. 41, n. 10, p. 4740-4744, 2003.

FONSECA, L. F. L.; SANTOS, M. V. Qualidade do leite e controle da mastite. São Paulo: Lemos Editorial, 2000. $175 \mathrm{p}$.

FREEMAN, D. J.; FALKINER, F. R.; KEANE, C. T. New method for detecting slime production by coagulase negative staphylococci. Journal of Clinical Pathology, London, v. 42, n. 8, p. 872-874, 1989.

FREITAS, M. F. L.; PINHEIRO JUNIOR, J. W.; STAMFORD, T. L. M.; RABELO, S. S. A.; SILVA, D. R.; SILVEIRA FILHO, V. M.; SANTOS, F. G. B.; MOTA, R. A. Perfil de sensibilidade antimicrobiana in vitro de Staphylococcus coagulase positivos isolados de leite de vacas com mastite no agreste do estado de Pernambuco. Arquivos de Biologia e Tecnologia, Curitiba, v. 72, n. 2, p. 171-177, 2005.

FTHENAKIS, G. G. Prevalence and etiology of subclinical mastitis in ewes of Sourthen Greece. Small Ruminant Research, Amsterdam, v. 13, n. 3, p. 293-300, 1994.

GATERMANN, S. G.; KOSCHINSKI, T.; FRIEDRICH, S. Distribution and expression of macrolide resistance genes in coagulase-negative staphylococci. Clinical Microbiolgy Infection, Malden, v. 13, n. 8, p. 777-781, 2007.

GRECO, C.; MASTRONARDI, C.; PAGOTTO, F.; MACK, D.; RAMIREZ-ARCOS, S. Assessment of biofilm-forming ability of coagulase-negative staphylococci isolated from contaminated platelet preparations in Canada. Transfusion Complications, Malden, v. 48, n. 5, p. 969-977, 2008.

HASSAN, K. A.; SKURRAY, R. A.; BROWN, M. H. Active export proteins mediating drug resistance in Staphylococci. Journal of Molecular Microbiology and Biotechnology, Basel, v. 12, n. 3-4, p. 180-196, 2007.

HERNANDES, G. S.; LUCHEIS, S. B. Monitoramento microbiológico da mastite ovina na região de Bauru (SP). Arquivos do Instituto Biológico, São Paulo, v. 68, n. 3, p. 395-403, 2006.

INSTITUTO BRASILEIRO DE GEOGRAFIA E ESTATÍSTICA- IBGE. Banco de dados agregados - Sistema IBGE de recuperação automática. 2012. Disponível em: <http://www.sidra.ibge.gov.br/bda/ pecua $/$ default.asp $\mathrm{t}=2 \& \mathrm{z}=\mathrm{t} \& \mathrm{o}=24 \& \mathrm{u} 1=1 \& \mathrm{u} 2=1 \& \mathrm{u} 3$ $=1 \& u 4=1 \& u 5=1 \& u 6=1 \& u 7=1>$. Acesso em: 24 maio 2012. 
JAFFE， W.; SWEENEY， H. M.; NATHAN， C.; WEINSTEIN, R. A.; KABINS, S. A.; COHEN, S. Identity and interspecific transfer of gentamicin-resistance plasmids in Staphylococcus aureus and Staphylococcus epidermidis. Journal of Infectious Diseases, Oxford, v. 141, n. 6, p. 738-747, 1980.

KATAYAMA, Y.; ROBINSON, D. A.; ENRIGHT, M. C.; CHAMBERS, H. Genetic background affects stability of mecA in Staphylococcus aureus. Journal of Clinical Microbiology, Washington, v.43, n. 5, p. 2380-2383, 2005.

KUMAR, R.; YADAV, B. R.; SINGH, R. S. Genetic determinants of antibiotic resistance in Staphylococcus aureus isolates from milk of mastitic crossbred cattle. Current Microbiology, New York, v. 60, n. 5, p. 379-386, 2009.

LEROY, C.; DELBARRE-LADRAT, C.; GHILLEBAERT, F.; ROCHET, M. J.; COMPÈRE, C.; COMBES, D. A marine bacterial adhesion microplate test using the DAPI fluorescent dye: a new method to screen antifouling agents. Letters in Applied Microbiology, Hoboken, v. 44, n. 4, p. 372-378, 2007.

LOWY, F. D. Antimicrobial resistance: the example of Staphylococcus aureus. Journal of Clinical Investigation, Michigan, v. 111, n. 9, p. 1265-1273, 2003.

MATHUR, T.; SINGHAL, S.; KHAN, S.; UPADHYAY, D. J.; FATMA, T.; RATTAN, A. Detection of biofilm formation among the clinical isolates of staphylococci: an evaluation of three different screening methods. Indian Journal of Medical Microbiology, Mumbai, v. 24, n. 1, p. 25-29, 2006.

MELO, C. B.; ALMEIDA, B. M.; OLIVEIRA, A. A.; AZEVEDO, H. C.; MELO, L. S. S.; MATA, S. S. Avaliação de uma metodologia profilática contra a mastite clínica em ovelhas da raça Santa Inês. Arquivo Brasileiro de Medicina Veterinária e Zootecnia, Belo Horizonte, v. 60, n. 4, p. 1011-1013, 2008.

MERINO, N.; TOLEDO-ARANA, A.; VERGARAIRIGARAY, M.; VALLE, J.; SOLANO, C.; CALVO, E.; LOPEZ, J. A.; FOSTER, T. J.; PENADÉS, J. R.; LASA, I. Protein A-Mediated Multicellular Behavior in Staphylococcus aureus, Journal of Bacteriology, Washington, v. 191, n. 3, p. 832-843, 2009.

MORONI, P.; PISONI, G.; VARISCO, G.; BOETTCHER, P. Effect of intrammary infection in Bergamasca meat sheep on milk parameters and lamb growth. Journal of Dairy Research, Cambridge, v. 74, n. 3, p. 340-44, 2007.

MURAKAMI, K. W.; MINAMIDE, W.; WADA, K.; NAKAMURA, E.; TERAOKA, H.; WATANABE, S. Identification of methicillin resistant strains of staphylococci by polymerase chain reaction. Journal of Clinical Microbiology, Washington, v. 29, n. 10, p. 22402244. 1991.

NACCARI, F.; MARTINO, D.; GIOFRE, F.; PASSANTINO, A.; DE MONTIS, P. Therapeutic efficacy of tilmicosin in ovine mammary infections. Small Ruminant Research, Amsterdam, v. 47, n. 1, p. 1-9, 2003.

NUNES, G. R.; BLAGITZ, M. G.; FREITAS, C. B.; SOUZA, F. N.; RICCIARDI, M.; STRICAGNOLO, C. R.; SANCHES, B. G. S.; AZEDO, M. R.; SUCUPIRA, M. C. A.; DELlA LIBERA, A. M. M. P. Avaliação de indicadores inflamatórios no diagnóstico da mamite ovina. Arquivos do Instituto Biológico, São Paulo, v. 75, n. 3, p. 271-278, 2008.

OLIVEIRA, L. G. L.; ALMEIDA, M. Z. P. R. B.; AFONSO, J. A. B.; LÁZARO, N. S.; MENDONÇA, C. L. Aspectos clínico-epidemiológicos e etiológicos da mastite clínica em ovelhas da raça Santa Inês no agreste meridional do Estado de Pernambuco. Archives of Veterinary Science, Curitiba, v. 12, p. 124-125, 2007. Suplemento.

OLSEN, J. E.; CHRISTENSEN, H.; AARESTRUP, F. M. Diversity and evolution of blaZ from Staphylococcus aureus and coagulase-negative staphylococci. Journal of Antimicrobial Chemotherapy, Oxford, v. 57, n. 3, p. 450460, 2006.

PHILLIPS, I.; CASEWELL, M.; COX, T.; GROOT, B. D.; FRIIS, C.; JONES, R.; NIGHTINGALE, C.; PRESTON, R.; WADDELL, J. Does the use of antibiotics in food animals pose a risk to human health? A critical review of published data. Journal of Antimicrobial Chemotherapy, Oxford, v. 53, n. 1, p. 28-52, 2004.

PITKÄLÄ, A.; HAVERI, M.; PYÖLÄRÄ, S.; MYLLYS, V.; HONKANEN-BUZALSKI, T. Bovine mastitis in Finland 2001 - prevalence, distribution of bacteria, and antimicrobial resistance. Journal of Dairy Science, Savoy, v. 87, n. 8, p. 2433-2441, 2004.

PYÖRÄLÄ，S.; TAPONEN，S. Coagulase-negative staphylococci - emerging mastitis pathogens. Veterinary Microbiology, Barcelona, v. 134, n. 1-2, p. 3-8, 2009.

QUINN, P. J.; CARTER, M. E.; MARKEY, B.; CARTER, G. R. Clinical veterinary medicine. London: MosbyYear, 1994. $648 \mathrm{p}$.

SANTOS, R. A.; MENDONÇA, C. L.; AFONSO, J. A. B.; SIM, L. C. V. Aspectos clínicos e características do leite em ovelhas com mastite induzida experimentalmente com Staphylococcus aureus. Pesquisa Veterinária Brasileira, Seropédica, v. 27, n. 1, p. 6-12, 2007. 
SAWANT, A. A.; GILLESPIE, B. E.; OLIVER, S. P. Antimicrobial susceptibility of coagulase-negative Staphylococcus species isolated from bovine milk. Veterinary Microbiology, Barcelona, v. 134, n. 1-2, p. 73$81,2009$.

STEFANAKIS, A.; BOSCO, C.; ALEXOPOULOS, C.; SAMARTZI, F. Frequency of subclinical mastitis and observation on somatic cell counts in ewes milk in Northern Greece. Animal Science, Cambridge, v. 61, n. 1, p. 69-76, 1995.

STEPANOVIC, S.; VUKOVIC, D.; DAKIC, I.; SAVIC, B.; VLAHOVIC, M. S. A modified microtiter-plate test for quantification of staphylococcal biofilm formation. Journal of Microbiology Methods, Amsterdam, v. 40, n. 2, p. 175-179, 2000.
TAPONEN, S.; PYÖRÄLÄ, S. Coagulase-negative staphylococci as cause of bovine mastitis-not so different from Staphylococcus aureus? Veterinary Microbiology, Barcelona, v. 134, n. 1-2, p. 29-36, 2009.

UDO, E. E.; JACOB, L. E.; MOKADAS, E. M. Conjugative transfer of high-level mupirocin resistance from Staphylococcus haemolyticus to other staphylococci. Antimicrobial Agents and Chemotherapy, Washington, v. 41, n. 3, p. 693-695, 1997.

VASUVEDAN, P.; NAIR, M. K. M.; ANNAMALAI, T.; VENKITANARAYANAN, K. S. Phenotypic and genotypic characterization of bovine mastitis isolates of Staphylococcus aureus for biofilm formation. Veterinary Microbiology, Barcelona, v. 92, n. 1-2, p. 179-185, 2003.

VAZ, A. K. Mastite em ovinos. A Hora Veterinária, Porto Alegre, v. 16, n. 93, p. 75-78, 1996. 
